Pacific Journal of Mathematic 


\section{ON A GENERALIZATION OF MARTINGALES DUE TO BLAKE}

\section{R. SUBRAMANIAN}

It is shown that any uniformly integrable fairer with time game (stochastic process) converges in $L_{1}$.

1. Introduction. Let $(\Omega, \mathscr{U}, P)$ be a probability space and $\left\{\mathscr{U}_{n}\right\}_{n \geqq 1}$ an increasing family of sub $\sigma$-algebras of $\mathscr{K}$. Let $\left\{X_{n}\right\}_{n \geqq 1}$ be a stochastic process adapted to $\left\{\mathscr{C}_{n}\right\}_{n \geqq 1}$ (see, [2, p. 65]). Following Blake [1] we refer to $\left\{X_{n}\right\}_{n \geqq 1}$ as a game and define

Definition. The game $\left\{X_{n}\right\}_{n \geqq 1}$ will be said to become fairer with time if for every $\varepsilon>0$

$$
P\left[\left|E\left(X_{n} / \mathscr{Q}_{m}\right)-X_{m}\right|>\varepsilon\right] \rightarrow 0
$$

as $n, m \rightarrow \infty$ with $n \geqq m$. Any martingale is, trivially, a fairer with time game and thus this concept generalizes that of martingales. Blake, in [1], gave a set of sufficient conditions under which any uniformly integrable fairer with time game $\left\{X_{n}\right\}_{n \geqq 1}$ is convergent in $L_{1}$. We show that these sufficient conditions are not needed; in fact, we show that any uniformly integrable, fairer with time game converges in $L_{1}$.

2. THEOREM 2.1. Any uniformly integrable fairer with time game $\left\{X_{n}\right\}_{n \geqq 1}$ converges in $L_{1}$.

Proof. To facilitate understanding, we break up the proof into a few important steps numbered (S1) through (S5). For every $m$ and $n \geqq m$ define $Y_{m, n}=E\left(X_{n} / \mathscr{U}_{m}\right)$. Let $\Gamma$ stand for the family $\left\{Y_{m, n}\right.$, for all $m$ and $n \geqq m\}$.

(S1) $\Gamma$ is uniformly integrable.

Since $\left\{X_{n}\right\}_{n \geqq 1}$ is uniformly integrable there exists a function $f$ defined on the nonnegative real axis which is positive, increasing and convex, such that

$$
\lim _{t \rightarrow \infty} \frac{f(t)}{t}=+\infty
$$

and $\sup _{n} E\left[f \circ\left|X_{n}\right|\right]<\infty$. (See [2, II T 22].) Now,

$$
\begin{aligned}
E\left[f \circ\left|Y_{m, n}\right|\right] & =E\left[f \circ\left|E\left(X_{n} \mid \mathscr{U}_{m}\right)\right|\right] \\
& \leqq E\left[f \circ E\left(\left|X_{n}\right| \mid \mathscr{U}_{m}\right)\right] \text { (since } f \text { is nondecreasing) } \\
& \leqq E\left[E\left(f \circ\left|X_{n}\right| / \mathscr{U}_{m}\right)\right] \\
& =E\left[f \circ\left|X_{n}\right|\right] .
\end{aligned}
$$


Therefore,

$$
\sup _{Y_{m, n} \in \Gamma} E\left[f \circ\left|Y_{m, n}\right|\right] \leqq \sup _{n} E\left[f \circ\left|X_{n}\right|\right]<\infty .
$$

Another application of II T 22 of [2] ensures that $\Gamma$ is uniformly integrable. Hence (S1).

(S2) Given $\varepsilon>0$, there exists $M$ such that for all $m \geqq M$, one has

$$
E\left(\left|X_{m}-Y_{m, n}\right|\right) \leqq 2 \varepsilon \text { for all } n \geqq m .
$$

Since $\Gamma$ is uniformly integrable given $\varepsilon>0$ there exists $\delta>0$ such that $P(A)<\delta$ implies $\int_{A}\left|Y_{m, n}\right| d P \leqq \varepsilon / 2$, for all $Y_{m, n} \in \Gamma$. Choose $M$ so large that $m \geqq M$ and $n \geqq m$ implies $P\left[\left|X_{m}-E\left(X_{n} / U_{m}\right)\right|>\varepsilon\right]<\delta$. Then, it is not difficult to see that

$$
E\left[\left|X_{m}-Y_{m, n}\right|\right] \leqq 2 \varepsilon \text { for all } m \geqq M \text { and } n \geqq m \text {. }
$$

(S3) For every fixed $m$, the sequence $\left\{Y_{m, n}\right\}$ converges in $L_{1}$ to an $\mathscr{U}_{m}$ measurable random variable $Z_{m}$.

Let $m \leqq n<n^{\prime}$.

$$
\begin{aligned}
E\left[\mid Y_{m, n}\right. & \left.-Y_{m, n^{\prime}} \mid\right]=E\left[\left|E\left(X_{n} \mid \mathscr{U}_{m}\right)-E\left(X_{n^{\prime}} \mid \mathscr{U}_{m}\right)\right|\right] \\
& =E\left[\left|E\left(X_{n}-X_{n^{\prime}} \mid \mathscr{U}_{m}\right)\right|\right] \\
& =E\left[\left|E\left(\left\{E\left(X_{n}-X_{n^{\prime}} \mid \mathscr{U}_{n}\right)\right\} / \mathscr{U}_{m}\right)\right|\right] \\
& \leqq E\left[E\left(\left\{\left|E\left(X_{n}-X_{n^{\prime}} \mid \mathscr{U}_{n}\right)\right|\right\} / \mathscr{U}_{m}\right)\right] \\
& =E\left[\left|E\left(X_{n}-X_{n^{\prime}} \mid \mathscr{U}_{n}\right)\right|\right] \\
& =E\left[\left|X_{n}-Y_{n, n^{\prime}}\right|\right] .
\end{aligned}
$$

Now from (S2) it follows that given $\varepsilon>0$ for all sufficiently large $n$ and $n^{\prime}$

$$
E\left[\left|Y_{m, n}-Y_{m, n^{\prime}}\right|\right] \leqq E\left[\left|\left(X_{n}-Y_{n, n^{\prime}}\right)\right|\right] \leqq 2 \varepsilon .
$$

Hence, for $m$ fixed, the sequence $\left\{Y_{m, n}\right\}$ is Cauchy in the $L_{1}$-norm. So, there exists, an integrable random variable $Z_{m}$, such that, $Y_{m, n} \underset{n \rightarrow \infty}{\stackrel{L_{1}}{\longrightarrow}} Z_{m}$. Without loss of generality we can take $Z_{m}$ to be $\mathscr{U}_{m}$ measurable. (Note that each $Y_{m, n}$ is $\mathscr{Q}_{m}$ measurable and there is a subsequence $\left\{Y_{m, n^{\prime}}\right\}$ converging almost surely to $Z_{m}$.)

(S4) $\left\{Z_{m}, \mathscr{U}_{m}\right\}_{m \geqq 1}$ is a uniformly integrable martingale.

The fact that $\left\{Z_{m}\right\}_{m \geqq 1}$ is uniformly integrable follows trivially because the closure in $L_{1}$ of a uniformly integrable collection is uniformly integrable. (See, [2, II T20].) To show $\left\{Z_{m}, \mathscr{K}_{m}\right\}$ is a martingale it is enough to show that for every $m, E\left(Z_{m+1} / \mathscr{U}_{m}\right)=Z_{m}$ a.s. Since 


$$
\begin{aligned}
E\left[\mid E\left(Y_{m+1, n} \mid \mathscr{U}_{m}\right)\right. & \left.-E\left(Z_{m+1} \mid \mathscr{U}_{m}\right) \mid\right] \\
& =E\left[\left|E\left\{\left(Y_{m+1, n}-Z_{m+1}\right) / \mathscr{U}_{m}\right\}\right|\right] \\
& \leqq E\left[E\left\{\left|\left(Y_{m+1, n}-Z_{m+1}\right)\right| / \mathscr{U}_{m}\right\}\right] \\
& =E\left[\left|Y_{m+1, n}-Z_{m+1}\right|\right] \longrightarrow 0 \text { as } n \longrightarrow \infty,
\end{aligned}
$$

there exists a subsequence $n^{\prime}$ of $\{n: \dot{n} \geqq m\}$ such that

$$
E\left(Y_{m+1, n^{\prime}} / \mathscr{U}_{m}\right) \stackrel{\text { a.s. }}{\longrightarrow} E\left(Z_{m+1} / \mathscr{U}_{m}\right) \text {. }
$$

We can assume (- if necessary, by choosing a further subsequence, -) that $Y_{m, n^{\prime}} \stackrel{\text { a.s. }}{\longrightarrow} Z_{m}$. Now,

$$
\begin{aligned}
E\left(Z_{m+1} \mid \mathscr{C}_{m}\right) & =\lim _{n^{\prime} \rightarrow \infty} E\left(Y_{m+1, n^{\prime}} \mid \mathscr{U}_{m}\right) \quad \text { a.s. } \\
& =\lim _{n^{\prime} \rightarrow \infty} E\left(\left\{E\left(X_{n^{\prime}} \mid \mathscr{U}_{m+1}\right)\right\} / \mathscr{C}_{m}\right) \quad \text { a.s. } \\
& =\lim _{n^{\prime} \rightarrow \infty} E\left(X_{n^{\prime}} \mid \mathscr{U}_{m}\right) \quad \text { a.s. } \\
& =\lim _{n^{\prime} \rightarrow \infty} Y_{m, n^{\prime}} \text { a.s. } \\
& =Z_{m} \quad \text { a.s. }
\end{aligned}
$$

Hence (S4). (S5) $\left\{X_{n}\right\}_{n \geqq 1}$ converges in $L_{1}$.

Since $\left\{Z_{n}, \mathscr{L}_{n}\right\}_{n \geqq 1}$ is an uniformly integrable martingale, there exists an integrable random variable $Z_{\infty}$ such that $Z_{n} \underset{n \rightarrow \infty}{\stackrel{L_{1}}{\longrightarrow}} Z_{\infty}$. We shall show that $X_{n} \underset{n \rightarrow \infty}{\stackrel{L_{1}}{\longrightarrow}} Z_{\infty}$. From (S3) and (S2) it is easy to check that given $\varepsilon>0$ there exists $M$ such that for all $m \geqq M$

$$
\int\left|X_{m}-Z_{m}\right| d P \leqq 2 \varepsilon
$$

Therefore, for sufficiently large $m$,

$$
\int\left|X_{m}-Z_{\infty}\right| d P \leqq \int\left|X_{m}-Z_{m}\right| d P+\int\left|Z_{m}-Z_{\infty}\right| d P \leqq 3 \varepsilon,
$$

say. Hence (S5) and the theorem.

Since any game (stochastic process) $\left\{X_{n}\right\}_{n \geqq 1}$ converging in $L_{1}$ can be taken to be a game fairer with time, by setting $\mathscr{C}_{n} \equiv \mathscr{C}_{\mathscr{C}}$ in $n$, we get the following corollary.

CoRollary 2.1. Let $\left\{X_{n}\right\}_{n \geqq 1}$ be a game. It converges in $L_{1}$ if and only if it is uniformly integrable and fairer with time with respect to some increasing family of sub $\sigma$-algebras $\left\{\mathscr{U}_{n}\right\}_{n \geqq 1}$ to which it is adapted.

Let $p>1$. 
Theorem 2.2. Let $\left\{X_{n}\right\}_{n \geq 1}$ be a fairer with time game with $\left\{\left|X_{n}\right|^{p}\right\}_{n \geqq 1}$ uniformly integrable. Then $\left\{X_{n}\right\}_{n \geqq 1}$ converges in $L p$.

Proof. Noting that the function $f$ defined on the nonnegative real axis by $f(t)=t^{p}$ is positive, increasing and convex and $\lim _{t \rightarrow \infty}(f(t) / t)=+\infty$, in view of II T 22 of [2], it is clear that $\left\{X_{n}\right\}_{n \geqq 1}$ is uniformly integrable. Hence by Theorem 2.1 it converges in $L_{1}$; in particular, $\left\{X_{n}\right\}_{n \geqq 1}$ converges in probability. Therefore, $\left\{X_{n}\right\}_{n \geqq 1}$ converges in $L_{p}$. (See Proposition II 6.1 of [3].)

CoRollaRY 2.2. The game $\left\{X_{n}\right\}_{n \geq 1}$ converges in $L_{p}$ if and only if $\left\{\left|X_{n}\right|^{p}\right\}_{n \geq 1}$ is uniformly integrable and $\left\{X_{n}\right\}_{n \geq 1}$ is fairer with time with respect to some increasing family of sub $\sigma$-algebras $\left\{\mathscr{U}_{n}\right\}_{n \geq 1}$ to which it is adapted.

REMARK. In view of our Theorem 2.1, the second convergence theorem of Blake in [1] becomes redundant.

\section{REFERENCES}

1. L. H. Blake, A generalization of martingales and two consequent convergence theorems, Pacific J. Math., 35 (1970), 279-283.

2. P. A. Meyer, Probability and Potentials, Blaisdell Publishing Company, Waltham, Massachusetts, 1966.

3. J. Neveu, Mathematical Foundations of the Calculus of Probability, Holden-Day, Inc., 1965.

Received March 10, 1972.

INDIAN STATISTICAL INSTITUTE

CALCUTTA-35, INDia 


\section{PACIFIC JOURNAL OF MATHEMATICS}

\section{EDITORS}

RICHARD ARENS (Managing Editor)

University of California

Los Angeles, California 90024

R. A. Beaumont

University of Washington

Seattle, Washington 98105
J. DUGUNDJI*

Department of Mathematics

University of Southern California

Los Angeles, California 90007

D. Gilbarg and J. Milgram

Stanford University

Stanford, California 94305

\section{ASSOCIATE EDITORS}
E. F. BECKENBACH
B. H. NeumanN
F. WOLF
K. YosHIDA

\section{SUPPORTING INSTITUTIONS}

UNIVERSITY OF BRITISH COLUMBIA
CALIFORNIA INSTITUTE OF TECHNOLOGY
UNIVERSITY OF CALIFORNIA
MONTANA STATE UNIVERSITY
UNIVERSITY OF NEVADA
NEW MEXICO STATE UNIVERSITY
OREGON STATE UNIVERSITY
UNIVERSITY OF OREGON
OSAKA UNIVERSITY

UNIVERSITY OF BRITISH COLUMBIA

UNIVERSITY OF CALIFORNIA

MONTANA STATE UNIVERSITY

UNIVERSITY OF NEVADA

OREGON STATE UNIVERSITY

OSAKA UNIVERSITY
UNIVERSITY OF SOUTHERN CALIFORNIA

STANFORD UNIVERSITY

UNIVERSITY OF TOKYO

UNIVERSITY OF UTAH

WASHINGTON STATE UNIVERSITY

UNIVERSITY OF WASHINGTON

\section{AMERICAN MATHEMATICAL SOCIETY} NAVAL WEAPONS CENTER

* C. R. DePrima California Institute of Technology, Pasadena, CA 91109, will replace J. Dugundji until August 1974. 


\section{Pacific Journal of Mathematics}

\section{Vol. 48, No. $1 \quad$ March, 1973}

Jan Aarts and David John Lutzer, Pseudo-completeness and the product of Baire

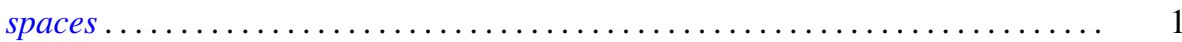

Gordon Owen Berg, Metric characterizations of Euclidean spaces ............ 11

Ajit Kaur Chilana, The space of bounded sequences with the mixed topology ..... . 29

Philip Throop Church and James Timourian, Differentiable open maps of

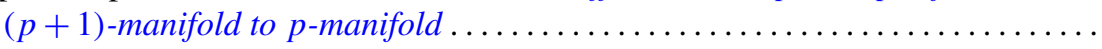

P. D. T. A. Elliott, On additive functions whose limiting distributions possess a finite

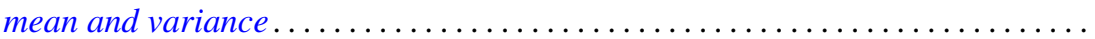

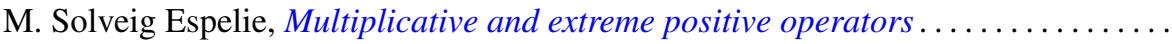

Jacques A. Ferland, Domains of negativity and application to generalized convexity

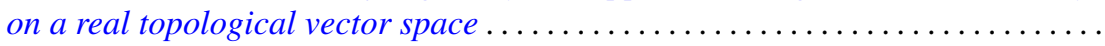

Michael Benton Freeman and Reese Harvey, A compact set that is locally holomorphically convex but not holomorphically convex ...............

Roe William Goodman, Positive-definite distributions and intertwining

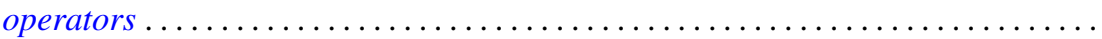

Elliot Charles Gootman, The type of some $C^{*}$ and $W^{*}$-algebras associated with

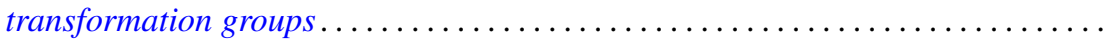

David Charles Haddad, Angular limits of locally finitely valent holomorphic

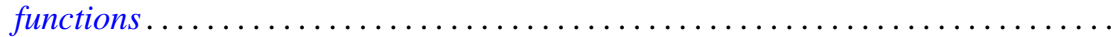

William Buhmann Johnson, On quasi-complements .

William M. Kantor, On 2-transitive collineation groups of finite projective spaces...

Joachim Lambek and Gerhard O. Michler, Completions and classical localizations of right Noetherian rings

Kenneth Lamar Lange, Borel sets of probability measures ......

David Lowell Lovelady, Product integrals for an ordinary differential equation in a Banach space

Jorge Martinez, A hom-functor for lattice-ordered groups .........

W. K. Mason, Weakly almost periodic homeomorphisms of the two sphere ....

Anthony G. Mucci, Limits for martingale-like sequences .......

Eugene Michael Norris, Relationally induced semigroups ...

Arthur E. Olson, A comparison of c-density and $k$-density ......

Donald Steven Passman, On the semisimplicity of group rings of linear groups.

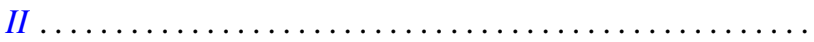

Charles Radin, Ergodicity in von Neumann algebras .

P. Rosenthal, On the singularities of the function generated by the Bergman operator of the second kind.

Arthur Argyle Sagle and J. R. Schumi, Multiplications on homogeneous spaces,

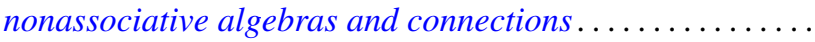

Leo Sario and Cecilia Wang, Existence of Dirichlet finite biharmonic functions on

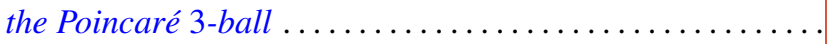

Ramachandran Subramanian, On a generalization of martingales due to Blake ..

Bui An Ton, On strongly nonlinear elliptic variational inequalities.

Seth Warner, A topological characterization of complete, discretely valued

fields. 